\title{
A colaboração entre pares em uma turma de adolescentes aprendendo inglês na escola pública
}

\author{
Edcleia Aparecida Basso (BASSO, Edcleia Aparecida) ${ }^{1}$ \\ Professora Doutora da Universidade Estadual do Paraná - UEPR Campo Mourão \\ edcleia@hotmail.com
}

Fernando Silvério de Lima (LIMA, Fernando Silvério de) ${ }^{2}$

Mestrando pela Universidade Federal de Viçosa - UFV

fernando_silverio@yahoo.com.br

\section{Resumo}

Neste artigo apresentamos alguns resultados alcançados por meio de uma pesquisa-ação realizada com alunos-adolescentes de escola pública. A análise dos dados foi norteada pela teoria sociocultural, quando, então, objetivamos entender o desenvolvimento daqueles alunos pela linguagem, focalizando as interações estabelecidas entre colegas e entre professor e alunos-adolescentes. Discutimos, especificamente, o construto teórico scaffolding, no viés da colaboração entre pares em atividades orais trabalhadas em sala de aula. Escolhemos como fonte primária para o presente estudo dados coletados por meio de gravações/filmagens de aulas, selecionando e transcrevendo alguns excertos para ilustrar a análise feita. Utilizamos também o diário de campo do aluno-professorpesquisador. Esses dados revelaram características peculiares e coerentes com a adolescência, fase pela qual os alunos passavam, tais como o desinteresse e apatia nas aulas, e apontaram também ocorrências de situações propícias à colaboração efetiva entre pares (colegas), que poderiam ter propiciado o desenvolvimento de ambos, mas que resultaram, na maioria delas, em aparente fracasso. Entretanto, ficou também evidenciado que, quando a atividade desperta a curiosidade, a motivação do alunoadolescente, ele se sente recrutado a participar da tarefa. Encerramos o estudo, certos da necessidade de mais pesquisas e estudos na área da Línguística Aplicada que focalizem o aluno-adolescente e seu desenvolvimento pela aprendizagem de uma nova língua no contexto público.

Palavras-chave: colaboração entre pares, alunos adolescentes, escola pública

\begin{abstract}
In this paper we present some results got from an action-research carried out with adolescents in a public school. The data were analyzed within a sociocultural approach.

\footnotetext{
${ }^{1}$ Líder do Grupo de Pesquisa PLE - O Professor de Língua Estrangeira: Contexto, Saberes e Práxis UEPR-Campo Mourão/CNPq.

${ }^{2}$ Bolsista da CAPES e pesquisador mestrando do Grupo de Pesquisa PLE - O Professor de Língua Estrangeira: Contexto, Saberes e Práxis UEPR-Campo Mourão/CNPq.
} 
We aimed at understanding the development of the adolescent-student through language, focusing on the interactions between peers and teacher/adolescent-student, discussing, specifically, the theoretical construct of scaffolding, analyzed through peer collaboration during oral activities developed in the classroom. We chose as primary data source some classes that were recorded, selecting and transcribing some parts to illustrate the analysis. The novice-researcher-teacher's diary was also used. Data revealed peculiar characteristics that were coherent with the students' lifetime, such as the lack of interest in classes, de-motivation, irony, among others. The study also pointed out adequate situations for effective peer collaboration (between classmates) which would have led to their development, but, on the contrary, have almost all of them turned out in apparent failure. However the analysis made it possible to say that, when the activity arouses his/her curiosity, interest or motivation, the adolescent-student feels recruited to engage in the task. We conclude the study sure of the need for more studies in Applied Linguistics focusing on the adolescent and his/her development through the process of learning a new language in the public school context.

Keywords: peer collaboration, adolescent student, public school

\section{Introdução}

Vários autores têm se pronunciado sobre o "drama de ensinar e aprender uma nova língua em escolas públicas (BASSO, 2001, 2008, entre outros). Basso e Lima (no prelo) apontam fatores subliminares altamente interferentes nesse processo. Ligados, sobretudo, à adolescência, tais fatores concorrem para que aulas, bem elaboradas e trabalhadas por professores bem intencionados, com adequada formação profissional, com compromisso sério com o ensino-aprendizagem no contexto público, redundem em fracasso, ou não alcancem nem se aproximem dos objetivos para elas traçados. Por estas razões, a incerteza de não acertar nas escolhas pedagógicas parece ser uma das poucas certezas de que o professor de alunos adolescentes pode ter. Cada aula é uma verdadeira incógnita, o esperado se torna inesperado e por vezes o inverso também é verdadeiro. Algumas atividades, pensadas como sem grande potencial para agradá-los, conseguem envolvê-los.

Por outro lado, apoiados nas pesquisas e estudos mencionados, podemos afirmar que na adolescência o sentimento de pertinência (MACOWSKI, 1993) é fundamental e que, por esta razão, a formação de grupos na sala de aula é uma constante com turmas de adolescentes. Eles precisam do suporte e do apoio dos seus pares dentro do grupo. $\mathrm{O}$ líder será sempre aquele que se apresenta como o mais forte, seja fisicamente ou

psicologicamente. Assim, de um jeito ou de outro, rindo ou chorando, brigando ou 
vivendo amizades intensas e companhias inseparáveis, o adolescente vai se estruturando no grupo e neste encontrando sua identidade.

Diante de tais constatações e com base na teoria sociocultural de Vygotsky (1989a, 1989b), que têm orientado nossos estudos e pesquisas, colocamos a pergunta que norteou a seleção dos dados e sua posterior análise: Como se caracteriza a interação e a colaboração entre pares (alunos-adolescentes) em aulas de língua inglesa em contextos públicos?

Para responder a tal questionamento, traçamos os seguintes objetivos:

- Observar uma turma de alunos-adolescentes de Ensino Médio em aulas de língua inglesa;

- Analisar o conceito de scaffolding em atividades em aulas de língua inglesa com alunos-adolescentes;

- Discutir como se dá a colaboração entre pares com alunos adolescentes em atividades de língua inglesa de escolas públicas.

Alcançados os objetivos propostos para a pesquisa, acreditamos que o artigo resultante pode trazer uma significativa contribuição para a Linguística Aplicada, especificamente para as áreas de formação de professores de línguas com base em estudos socioculturais de natureza vygotskiana .

\section{Metodologia da pesquisa}

Entendemos metodologia de pesquisa como "o caminho do pensamento e a prática exercida na abordagem da realidade”. Nela estão incluídas as concepções teóricas de abordagem e o conjunto de técnicas, considerando que "a metodologia deve dispor de um instrumental claro, coerente, elaborado, capaz de encaminhar os impasses teóricos para o desafio da prática" (MINAYO, 2000, p. 16). A pesquisa seguiu a linha qualitativa, de cunho interpretativista (BASSO, 2001; ERICKSON, 1986), uma vez que se aprofundou no mundo dos significados das ações e relações humanas ocorridas durante o processo de ensino-aprendizagem, mediadas pela linguagem.

O tipo de pesquisa escolhido foi a pesquisa-ação que é, segundo Thiollent (1997), um ramo da pesquisa social de base empírica, concebida e realizada em estreita associação com uma ação ou com a resolução de um problema coletivo. Essa ação ou 
solução envolve, de modo cooperativo ou participativo, pesquisadores e participantes representativos da situação ou do problema. Nesse tipo de investigação, o pesquisador assume a responsabilidade não apenas de assistir os atores envolvidos através da geração de conhecimento, mas também da aplicação deste conhecimento.

A técnica para a busca nos dados e a consequiente análise adveio dos princípios da Dialética, que é a arte do diálogo, do questionamento, do procedimento argumentativo. Lakatos (2007, p. 101) diz que "o objetivo da dialética é encontrar sempre vias de se transformar, de desenvolver, o fim de um processo é sempre o começo de outro". Justificamos essa opção pelo fato de a Dialética abarcar não somente o sistema de relações que constrói o modo de conhecimento exterior ao sujeito, mas também as representações sociais que traduzem o mundo dos significados (GIL, 1999, p.25). O fenômeno ou o processo social tem que ser entendido nas determinações e transformações dadas pelos sujeitos, nas contradições que se transcendem, dando origem a novas contradições que passam, por sua vez, a requerer novas soluções. (CHIZZOTTI, 2003; GIL, 1999)

A pesquisa foi realizada durante o período de regência de APP, o que nos possibilitou a observação e o trabalho pedagógico com alunos-adolescentes, apresentando-lhes o que pensávamos que pudesse ser relevante para criar condições para uma aprendizagem que de certa forma os levasse a uma realização pessoal, ou, no dizer de Almeida Filho (2005), se constituísse como uma experiência reconhecida como válida e significativa.

Os sujeitos primários da pesquisa foram o aluno-professor-pesquisador (APP) e os alunos-adolescentes de uma escola pública, representados nas transcrições pela letra inicial de seu nome. A professora titular da turma foi também sujeito do estudo, embora não tenha participado diretamente no recorte feito para o presente artigo.

APP foi especialmente escolhido para esse estudo por apresentar os requisitos fundamentais propostos, uma vez que reunia as competências necessárias e ideais em um professor de LE, propostas por Basso (2001, 2008), tais como: competência discursiva na língua-alvo, e competência profissional desejável e esperada em um concluinte do curso de Letras. Além disso, APP tinha dois requisitos que os pesquisadores consideravam essenciais para o desenvolvimento da pesquisa: ter tido experiência anterior no ensino de LE com adolescentes e um bom domínio da teoria vygotskiana, advindo de participação do Programa de Iniciação Científica e do Grupo de Pesquisa PLE: O professor de língua estrangeira: saberes, contextos e práxis. 
Participaram da pesquisa 27 alunos matriculados em um primeiro ano diurno do Ensino Médio de uma escola pública situada em um bairro periférico de uma cidade do noroeste do Paraná. Os alunos tinham entre 15 e 18 anos, e eram filhos de pais trabalhadores com renda familiar baixa. Nenhum deles fazia ou já tinha feito um curso de idiomas fora da escola.

Os instrumentos utilizados para a coleta de dados foram aqueles preconizados pela pesquisa qualitativa: questionário, entrevistas, filmagens de aulas e respectivas transcrições, relatório de cada aula observada e diário do aluno-professor-pesquisador. Para este artigo, no entanto, fizemos um recorte, objetivando verificar como se caracterizava as interações entre alunos-adolescentes, numa perspectiva vygotskyana. Para tanto foram utilizadas como fonte primária a filmagem e transcrições de trechos considerados fundamentais para a análise dos dados, bem como o diário do APP.

A coleta de dados aconteceu de março a novembro de 2009 e foi organizada em duas fases distintas: na primeira, acontecida nos dois primeiros bimestres, APP acompanhou a turma por meio de observações registradas no diário de campo e aplicou um questionário no final dessa fase. Na segunda fase, acontecida no terceiro bimestre, APP assumiu a docência de uma unidade completa com essa turma, e os dados passaram a ser coletados sob a forma de filmagem de algumas aulas, diário de campo, e, por fim, através de uma entrevista com a professora regente da turma.

Partindo de sugestões dos próprios alunos, obtidas nas respostas ao questionário semi-aberto aplicado no final da primeira fase $^{3}$, bem como em conversas informais com os alunos, APP propôs o trabalho com atividades orais em algumas das aulas, que foram filmadas com auxílio da professora regente. Tivemos como objetivo analisar as interações ocorridas entre o grupo, com foco no papel da aprendizagem colaborativa entre pares (professor $\mathrm{x}$ alunos; aluno $\mathrm{x}$ aluno), tendo como referencial teórico, pesquisas já desenvolvidas na Linguística Aplicada, sobretudo aquelas iluminadas por pressupostos socioculturais, tais como Basso (2008a), Basso e Lima (no prelo), Donato (1994), Ferreira (2000, 2008), John-Steiner e Mahn (1996), Lantolf e Appel (1994), Lantolf e Thorne (2000), Smagorinski (2007) entre outros autores.

Enfim, o contexto educacional e estrutural - a escola pública - dispunha de recursos tecnológicos considerados como importantes para um bom desenvolvimento do

\footnotetext{
${ }^{3} \mathrm{O}$ questionário foi aplicado com objetivo de delinear o perfil da turma, conhecer os tipos de atividades que eles gostavam de realizar, e algumas crenças sobre o ensino na escola pública. Este último aspecto não será contemplado neste artigo por questões de escopo.
} 
ensino-aprendizagem de todas as disciplinas como Internet, TV multimídia nas salas de aula. Também colocava a disposição para as aulas aparelhos de som, retroprojetores e materiais para impressão. Os diretores e coordenadores estiveram sempre abertos ao diálogo e às novas alternativas para o ensino de língua inglesa.

\section{Referencial teórico}

Ao procuramos por pesquisas recentes na Linguística Aplicada com foco na escola pública, observamos que havia uma grande lacuna nesta área e que tal lacuna se tornava ainda maior quando se tratava de estudos focalizando o aluno-adolescente de escola pública brasileira, retratando e discutindo o processo de ensino-aprendizagem de línguas com estes alunos. Entre as poucas existentes encontramos Macowski (1993) e Basso (2008). As conclusões chegadas nestes estudos dizem ser esse o grande período de transição na vida do ser humano, marcado por profundas mudanças afetivas, biológicas, cognitivas, psicológicas e sociais que podem estar relacionadas às experiências vivenciadas tanto na escola como fora dela, mas que irão certamente afetar o seu desenvolvimento escolar.

Sabemos ser alunos-adolescentes o público da grande maioria dos professores que atuam no período diurno nos últimos anos do Ensino Fundamental do Brasil, assim como conhecemos as dificuldades enfrentadas para estes professores realizarem sua prática pedagógica com este público. Por esta razão fizemos a opção de colocar o alunoadolescente sob nossa lente, e neste presente artigo, escolhemos clarear um pouco mais o construto teórico do scaffolding, utilizado tanto na Educação quanto na Linguística Aplicada, inspirado nos pressupostos socioculturais de Vygotsky (1989a, 1989b) e desenvolvido pelos seus seguidores (DONATO, 1994; FERREIRA, 2008; LANTOLF; THORNE, 2000), e tomando aqui sob análise nas interações e colaboração entre pares.

\subsection{O ensino-aprendizagem de línguas com adolescentes}

Problemas como a indisciplina e o desinteresse têm sido a tônica ao se falar de adolescentes, considerando também que pais e professores geralmente compreendem esta fase como um período marcado por conflitos, tensões e stress (ARNETT, 1999; BUCHANAN et al, 1990). Portanto, não foi surpresa constatar que os mesmos 
problemas aparecem sempre nas pesquisas que focalizam adolescentes aprendendo outras línguas (língua inglesa em sua maioria), assim como também é frequente a constatação de que a prática docente encontra-se muito comprometida devido a tais fatores (BASSO, 1999, 2008; BASSO; LIMA, no prelo, MACOWSKI, 1993).

Em meio aos conflitos em sala de aula, o aluno adolescente passa por um período de transformações de ordem biológica, cognitiva, e emocional (BASSO, 2008; ZARRET; ECCLES, 2006), cuja tensão pode ser compreendida pela transição que acontece entre a dependência dos pais até a vida adulta independente e auto-suficiente (ZIMMERMAN; CLEARY, 2006). Todas essas mudanças afetam de alguma forma diferentes domínios da vida do adolescente, conforme discutido em Schunk e Meece (2006). Surgem (I) conflitos nas relações familiares e incompreensão entre pais e filhos. Aparecem (II) as afiliações de grupo em que os alunos buscam a formação de uma turma, por questões de afinidade e interesse. Uma vez em grupo, eles se sentem fortalecidos o bastante para estabelecer tanto a indisciplina quanto a indiferença, características marcantes e presentes quando se trata de aulas com adolescentes. Outro domínio que se transforma é (III) o do ambiente escolar, especificamente no caso ou de turmas concluintes do Ensino Fundamental ou de turmas iniciantes do Ensino Médio, que neste último caso é marcada por uma cobrança ainda maior por parte dos professores e demais segmentos do contexto educacional, que esperam mais de seus alunos adolescentes, uma vez que agora eles estão mais velhos.

Pensando nos professores, especificamente, a cada ano estes estão em contato com diversas turmas repletas de adolescentes e terão que lidar com todos esses fatores, além de fatores contextuais recorrentes, como poucas aulas semanais, levando-os a terem muitas turmas para cumprir a carga horária semanal de vinte horas por turno. Esses fatores afetam diretamente o professor de LE e consequentemente a forma como conduz suas aulas. Richards e Pennington (1998) discutem esta questão em um estudo realizado com professores de LE em início de profissão em Hong Kong. Os autores pontuam que, no primeiro ano de trabalho, ao ter que lidar com fatores como indisciplina dos alunos, turmas numerosas, tipo de material usado, alunos desmotivados, dentre outros, é comum que os próprios professores se tornem desmotivados. Deixam então de lado a criação e a inovação, cedendo espaço aos métodos tradicionais, que muitas vezes conseguem silenciar as turmas mais barulhentas, sendo, por vezes a única alternativa viável àquele contexto. Esta atitude é chamada por Basso (2008, p. 138) de estratégia afetiva. 
Lamb (2004), em um estudo com alunos adolescentes de escola pública na Indonésia, aponta um fator interessante do contexto observado. Por meio de entrevistas individuais, o autor constatou que o aluno asiático é bastante preocupado com a aceitação de seu professor, sendo muitas vezes mais importante para o aluno que o professor goste dele, mesmo que ele não goste do professor (p. 237-238). Mesmo assim, situações em que os alunos ignoram o professor ou o que foi proposto por ele também são comuns, como também reportam pesquisas brasileiras anteriormente citadas.

Mesmo com os percalços como indisciplina, desmotivação, indiferença, ironias, sono, letargia, que geralmente predominam nas pesquisas com adolescentes, existem alguns aspectos muito positivos que devem ser maximizados pelos professores. Podemos ilustrar, apontando as características inerentes aos adolescentes, que atuam como cooperantes para sua aprendizagem e desenvolvimento de habilidades que serão importantes na vida adulta (cf. SCHUNK; MEECE, 2006; ZIMMERMAN; CLEARY, 2006). São capazes de aprender uma nova língua de modo formal, com base no ensino consciente e/ou gramatical, assim como podem aprendê-la de forma natural, como as crianças. Têm excelente percepção auditiva, o que os leva a identificar os sons, as palavras contidas em músicas, filmes com muita facilidade. (MACOWSKI, 1993). Nesta perspectiva, concordamos com Bandura (2006, p.10), quando afirma que "os adolescentes precisam se comprometer com os objetivos que lhes dão um propósito e um senso de realização pessoal". ${ }^{4} \mathrm{Na}$ seção a seguir, apresentamos os pressupostos teóricos que embasaram a elaboração das atividades e a análise das interações nas aulas de inglês em uma escola pública.

\subsection{Perspectivas vygotskianas e a teoria sociocultural}

Os trabalhos do psicólogo soviético Lev Semenovich Vygotsky (1896-1934) que constituem a teoria sociocultural (cf. LANTOLF; THORNE, 2000) têm orientado diversos trabalhos no exterior (COLE; WERTSCH, 2002; LANTOLF; APPEL, 1994; LANTOLF; THORNE, 2000, SMAGORINSKY, 2007; VERENIKINA, 2003, 2008,

\footnotetext{
4 “Adolescents need to commit themselves to goals that give them purpose and a sense of accomplishment."
} 
entre outros) e no Brasil (FERREIRA, 2000, 2008; LIMA; BASSO, 2009, MACOWSKI, 1993) em pesquisas de segunda língua (L2) e Línguas estrangeiras (LE). ${ }^{5}$

Em seus estudos de Psicologia com crianças, Vygotsky (1989a) ressaltou a importância da colaboração e assistência advindas das pessoas que fazem parte do seu contexto, considerando o papel fundamental da linguagem no desenvolvimento cognitivo e social das funções psicológicas superiores, as quais são socialmente e culturalmente determinadas nesta perspectiva, conforme aponta Marchenkova (2005, p. 177).

Para Vygotsky, o aprendizado precede o momento em que os aprendizes passam a fazer parte do contexto escolar, contudo, o pesquisador reconhece que a educação escolar traz contribuições fundamentalmente novas (VYGOTSKY, 1989a, p. 94), dependendo de como a escola vai perceber e trabalhar o conhecimento trazido pelo aluno e o novo a ser ali sistematizado. Nesta perspectiva, o autor introduz a chamada Zona de Desenvolvimento Proximal ou Potencial (ZDP), um dos seus construtos teóricos mais estudados em nível interdisciplinar (SMAGORISNKI, 2007) e a seguir explicitado.

Vygotsky concebe o desenvolvimento em dois níveis: (I) o nível de capacidade autônoma do aprendiz na solução de tarefas, também conhecido por nível real ou efetivo, e (II) o nível das capacidades embrionárias (ZPD). Neste nível o aprendiz pode contar com a assistência de um par mais experiente, normalmente o professor ou um colega com mais conhecimento no assunto, sempre mediados pela linguagem (COLE; WERTSCH, 2002). Portanto, o autor conclui que a ZDP "é a distância entre o nível de desenvolvimento real, e o nível de desenvolvimento potencial" (VYGOTSKY, 1989a, p. 97).

Refletindo sobre o impacto dos textos de Vygotsky na Educação e no ensino de línguas, Lantolf e Thorne (2000, p. 267) concluem que:

A ZDP não é apenas um modelo do processo de desenvolvimento, mas também uma ferramenta conceitual que os educadores podem usar para compreender aspectos das capacidades emergentes dos aprendizes que estão em estágios iniciais de maturação. Desta forma, quando usado proativamente, os professores que usam o conceito da ZDP como um diagnóstico têm potencial para criar condições que podem dar origem a formas específicas de desenvolvimento no futuro.

\footnotetext{
${ }^{5}$ Vide Ferreira (2000) para uma síntese dos principais estudos em Linguística Aplicada realizadas no exterior na perspectiva da teoria sociocultural na década de 90 .
} 
Compreendendo esse construto e pensando em seu papel na aprendizagem, outros autores, discutidos a seguir, propõem o conceito do scaffolding, para estudar as interações entre pares no processo de aprendizagem de L2 e LE.

\subsubsection{O construto teórico do scaffolding}

Os estudos sobre colaboração entre pares foram introduzidos na Psicologia por Wood, Bruner e Ross (1976), em trabalhos sobre a colaboração e interação entre crianças, e na Linguística Aplicada figuram em trabalhos como os de Donato (1994), Ferreira (2008) e Verenikina (2003, 2008).

Wood, Bruner e Ross (1976) desenvolveram o conceito no estudo de interações entre adultos e crianças com idades entre três, quatro e cinco anos, em que os pequenos aprendizes recebiam auxílio para realizar tarefas, salientando que a colaboração é favorecida pela capacidade diferencial que cada ser humano tem de aprender e também de ensinar (a fazer). Frente a tal pressuposto, os autores definem o scaffolding como sendo:

[um] processo que permite à criança ou aprendiz resolver um problema, realizar uma tarefa, ou alcançar um objetivo que estaria além de seus esforços, se não tivesse auxílio. O scaffolding consiste essencialmente em o adulto "controlando" aqueles elementos da tarefa que inicialmente estão além da capacidade do aprendiz, permitindo assim que ele se concentre e complete apenas os elementos que estejam dentro dos limites de sua competência. (WOOD; BRUNER; ROSS, 1976, p.90) ${ }^{6}$

De acordo com o Longman Dictionary of Language Teaching and Applied Linguistics, o construto teórico scaffolding pode ser definido como:

o suporte oferecido aos aprendizes que lhes permite realizar tarefas que estão além de sua capacidade. Inicialmente na aprendizagem de uma língua, os aprendizes podem ser incapazes de produzir certas estruturas dentro de uma única expressão, mas podem construí-las por meio de interação com outros falantes. ${ }^{7}$ (RICHARDS; SCHMIDT, 2002, p. 466)

\footnotetext{
${ }^{6}$ [a] process that enables a child or novice to solve a problem, carry out a task or achieve a goal which would be beyond his unassisted efforts. This scaffolding consists essentially of the adult "controlling" those elements of the task that are initially beyond the learner's capacity, thus permitting him to concentrate upon and complete only those elements that are within his range of competence"

7 "The support provided to learners to enable them to perform tasks which are beyond their capacity. Initially in language learning, learners may be unable to produce certain structures within a single utterance, but may build them through interaction with another speaker."
} 
Como podemos perceber, o verbete no dicionário de Linguística Aplicada remete ao conceito apresentado em Wood, Bruner e Ross (1976). Com este suporte, os aprendizes são capazes de lidar com suas limitações, até o momento em que tal assistência não se faça mais necessária. Isso acontece quando o conhecimento que era potencial firma-se como conhecimento efetivo, pronto para ser usado sem apoio ou mediação de outrem.

No trabalho pioneiro na Psicologia sobre o scaffolding, Wood, Bruner e Ross (1976 apud DONATO, 1994) apontam seis características deste construto:

Tabela 1. Características do Scaffolding

\begin{tabular}{|l|l|}
\hline $\mathbf{0 1}$ & Recrutar o interesse na tarefa \\
\hline $\mathbf{0 2}$ & Simplificar a tarefa \\
\hline $\mathbf{0 3}$ & Manter a busca pelo objetivo \\
\hline $\mathbf{0 4}$ & $\begin{array}{l}\text { Marcar as características críticas e discrepâncias entre o que tem } \\
\text { sido produzido e solução ideal. }\end{array}$ \\
\hline $\mathbf{0 5}$ & Controlar a frustração durante a solução do problema, e \\
\hline $\mathbf{0 6}$ & Demonstrar uma versão idealizada do ato a ser realizado. \\
\hline
\end{tabular}

Donato (1994) foi pioneiro na pesquisa na LA em tentar aplicar o construto do scaffolding ao ensino de línguas, ao conduzir um estudo que focalizou a construção coletiva das experiências de aprendizagem no contexto universitário (p. 34). Baseado no caráter social dos estudos vygotskianos, o autor lança a hipótese de que, na aprendizagem de uma nova língua, os aprendizes podem ser capazes de "oferecer uns aos outros o mesmo tipo de suporte e direção que os adultos oferecem às crianças $\left(\right.$ p.39) ${ }^{8}$. Vale ressaltar que o contexto estudado era o universitário, com alunos aprendendo Francês em um semestre de faculdade. Conforme o dizer de Lamb (2004, p. 229), as pesquisas com alunos universitários geralmente consideram que esses “possuem a maturidade necessária para se responsabilizar por sua aprendizagem (...)”.

Por meio de análise de protocolos, Donato (1994) analisou evidências de scaffolding entre os pares de alunos ao longo das aulas. Os resultados apontam para o que o autor define como collective scaffolding em que os alunos são capazes de oferecer auxílio mútuo e efetivo. Entretanto, é necessário atentarmos para uma ressalva de Ferreira (2008) a respeito das condições de interação geralmente estudadas na aquisição de segunda língua. De acordo com a autora, os alunos participantes do estudo de Donato

\footnotetext{
8 “...learners can, in certain circumstances, provide the same kind of support and guidance for each other that adults provide children."
} 
(1994) eram do ensino superior e poderiam estar bastante motivados para a aprendizagem, ou seja, estavam conscientes de seu papel para solicitar a assistência do par mais experiente na língua alvo em momentos de dificuldade. Isso, porém, não acontece em todos os contextos. No contexto da educação básica e na escola pública, caso do presente artigo, é muito comum encontrar falta de motivação para com a aprendizagem, a não consciência do papel de colaboração entre aprendizes, grande defasagem de conhecimento lingüístico e discursivo na nova língua, entre outros problemas. Isso não representa necessariamente a impossibilidade de haver efetividade no trabalho em pares e em grupos com base no construto de scaffolding nas interações na escola pública, mas revela as limitações para que ele ocorra ao longo das atividades, sobretudo na língua-alvo.

\section{Análise de dados}

Conforme dito anteriormente neste artigo, optamos, durante o período de regência compartilhada, por promover entre os alunos momentos de maior interação na língua inglesa, considerando algumas variáveis como o uso de textos voltados à realidade deles, por exemplo, buscando com esta decisão recrutar/despertar seu interesse em participar das aulas.

Assim, com base nos estudos já citados, passamos nesse momento à análise de trechos de interações entre alunos-adolescentes observando:

(I) os momentos em que a interação entre alunos é comprometida pelo desinteresse com a atividade ou falta de conhecimento na língua alvo; e

(II) momentos em que os alunos demonstram ser "recrutados" ou, em outras palavras, envolvem-se com a atividade.

Focalizamos neste trabalho principalmente a realização de atividades orais e as reações dos alunos ao ter que (tentar) interagir na língua alvo de acordo com a proposta da aula. Lembramos que os excertos aqui apresentados foram transcritos a partir das aulas gravadas em vídeo e que as letras utilizadas são as iniciais dos seus nomes.

O primeiro excerto (Quadro 1) consiste em uma das interações registradas durante uma aula cujo objetivo era uma entrevista a ser realizada em pares. Cada aluno possuía uma pequena ficha com seus dados pessoais e preferências musicais (artistas e estilos favoritos). Os alunos deveriam entrevistar uns aos outros, conhecendo um pouco 
mais seus colegas de sala, por meio de informações pessoais conseguidas. É necessário frisarmos, conforme registrado em vídeo, que APP enfatizou diversas vezes que os alunos poderiam se levantar e que deveriam caminhar pela sala e entrevistar diferentes colegas, inclusive alguns de outras turmas. No entanto, a atividade se concentrou apenas nos grupos menores já estabelecidos antes mesmo de o professor (APP) iniciar a aula, com pouquíssimas exceções e eles não quiseram sair para entrevistar colegas de outras turmas.

Buscando explicação na teoria, Basso (2008, p.130) afirma que, para o aluno adolescente, permanecer na sua "turma" é fundamental, pois ela passa a representar "um meio de satisfação pessoal, de descarga emocional, de palco para sua ideias". E por isso, durante as aulas, pudemos notar a preferência em participar de atividades somente com colegas do mesmo grupo, sem caminhar pela sala como havia sido sugerido pelo professor. Além disso, e com base em Macowski (1993) e em Basso (2008), devemos registrar também o peso que tem a timidez, sobretudo no aluno-adolescente, que não gosta de se expor, de ser ridicularizado no caso de cometer algum erro.

\section{Quadro 1. Excerto 1}

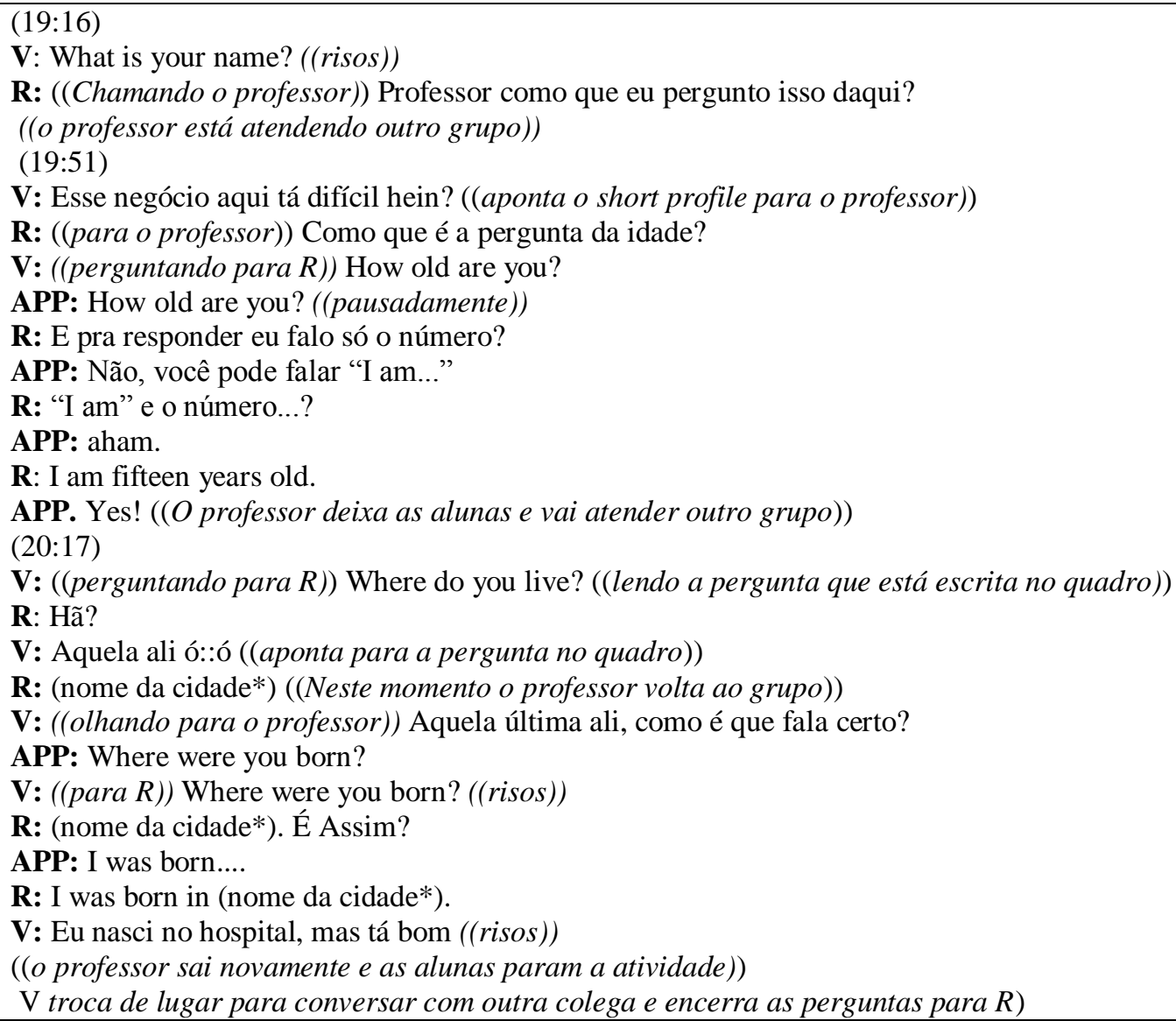


Neste primeiro excerto, percebemos que $\mathrm{V}$ inicia a entrevista, no entanto, $\mathrm{R}$ ignora a pergunta da colega e de início já recorre ao professor (APP). Ao chegar até as duas alunas, $\mathrm{V}$ verbaliza a dificuldade da atividade (que exigia do aluno fazer as perguntas em LI). No entanto, quando a aluna R questiona APP sobre como perguntar a idade, prontamente $\mathrm{V}$ arrisca um palpite certeiro. O professor então repete a sentença pausadamente para a aluna. A interação neste caso foi mediada pela língua materna, porque o objetivo do professor foi solucionar as dúvidas para que $\mathrm{R}$ respondesse a pergunta de $\mathrm{V}$ na língua-alvo. No ensino de LE, ter consciência do papel da língua materna como função mediadora de apoio (ALMEIDA FILHO, 2005, p. 79) é de extrema relevância para o professor, que passa a reconhecer os erros e as limitações atuais "como sinais de crescimento da capacidade de usar a língua alvo". Dessa forma, conforme também sugere Ferreira (2000, p. 36), devemos "atentar mais para o que nossos alunos fazem ao realizar uma determinada tarefa e, além disso, vemos o uso de L1 durante essas interações como um instrumento de mediações, de busca de autoregulação na tarefa, especialmente para os níveis iniciais".

Por fim, $\mathrm{R}$ consegue responder a pergunta após todo o auxílio recebido e o professor deixa a dupla, dirigindo-se para outro grupo.

Mesmo com a saída de APP, a câmera continuou focalizando a interação do par na atividade. $\mathrm{V}$ questiona $\mathrm{R}$ sobre o local onde nasceu, e a colega não compreende a pergunta (em LI). V evita ter que repetir e acaba apenas apontando a pergunta no quadro. Desta vez, sem ser solicitado pelos alunos, o professor retorna ao grupo para acompanhar a atividade do par. Nesta interação, V controla os turnos realizando as perguntas em língua inglesa para R. Além disso, como é possível perceber na gravação, os risos são constantes sempre que $\mathrm{V}$ termina uma pergunta. Interpretamos os risos aqui como um estranhamento ao utilizarem a LI oralmente, já que o foco das aulas antes que APP assumisse a turma (conforme registrados no diário do professor-pesquisador) estava na leitura e na tradução de textos. No momento e pelo contexto, percebemos haver também um certo descomprometimento com a atividade. Não queremos com isso enfatizar ainda mais o discurso comum, ao nos referirmos sobre adolescentes, de que “eles não querem nada com nada" (cf. BASSO, 1999), mas chamar a atenção para a necessidade de que o adolescente reconheça sua aprendizagem como válida, que tem objetivos definidos (BANDURA, 2006), para que possa se engajar, sobretudo no papel importante da colaboração entre os pares. Nessas situações ele pode se ajudar e ajudar seu colega na construção do conhecimento na nova língua, e ambos, conscientes de sua 
responsabilidade, podem se auxiliar nos momentos de dificuldade, sendo isso "fundamental para o desenvolvimento cognitivo do ser humano" (FERREIRA, 2000, p. 21).

Nesta interação analisada percebemos que o professor foi quem atuou como o par mais experiente. Ele oferece o maior incentivo ao uso da língua alvo, muito provavelmente por ter mais conhecimento e domínio da mesma. É possível perceber também que o par desviava o foco da atividade no momento em que o professor deixava a dupla, e ao retornar, a dupla se engajava novamente na atividade, pedindo auxílio inclusive do professor. Fica evidente a dependência do professor, querendo-o sempre por perto, realmente conferindo e garantindo o envolvimento dos alunos com a atividade, conforme também pode ser observado em outras interações, como no trecho a seguir.

\section{Quadro 2. Excerto 2}

( duas alunas, D e G, tentam realizar a atividade. Ao perceber que APP está conversando com a dupla ao lado elas também o chamam.)

D: Professor, vem aqui depois.

APP: Ok. A minute, please.

((o professor se aproxima da dupla))

D: Como é que eu pergunto pra G se ela gosta de Fresno? Eu sei que ela gosta de Pop rock, mas eu quero saber pra nome de banda. ((o professor não havia dado esse exemplo e a aluna questionou))

APP: Tenta aproveitar a pergunta mais geral "What bands or groups do you like?" e faz ela sair a partir disso. Como que você faria?

D: Bands you like Fresno? ((olhando para o professor))

APP: Não. Tenta de novo. Tá quase lá, tenta esquecer o bands.

( $(G$ que apenas observava interrompe e dá um palpite $))$

G: Tem que o usar esse "do you"?

APP: Yes. Isso mesmo.

G: Então fica, do you like Fresno?

APP: Ae! Very good.

D: Ah, beleza.

APP: Agora pode perguntar e continuem, ok?

(o professor deixa a dupla continuar a atividade)

A aluna D queria fazer uma pergunta para G sobre um artista, no entanto, não sabia como, uma vez que o exemplo não foi contemplado durante a explicação de APP. Por isso, ela pede para que ele se aproxime e passa então a explicar sua dúvida. Na sua primeira tentativa, ela constrói uma pergunta errada, e o professor incentiva que ela continue mesmo assim. Sua colega (G) interrompe com uma nova pergunta, que é confirmada pelo professor como o caminho à primeira questão que D gostaria de fazer. Por fim, mediadas pela assistência do professor, D consegue a resposta para sua indagação, o que lhe permite continuar a atividade. 
Em seu estudo sobre a colaboração entre pares, Ferreira (2008) discute como algumas variáveis, tais como (I) falta de conhecimento da língua alvo e (II) falta de compreensão consciente do papel da colaboração comprometem o que na literatura de LA é visto como uma ajuda ou um apoio efetivo, ou seja, que resulte na aprendizagem de um dos pares. Podemos perceber nessa interação que o professor era a única fonte na qual os alunos buscavam auxílio, raros foram os momentos em que um colega pede/oferece auxílio para a outra espontaneamente, conforme é possível observar no terceiro excerto.

\section{Quadro 3. Excerto 3}

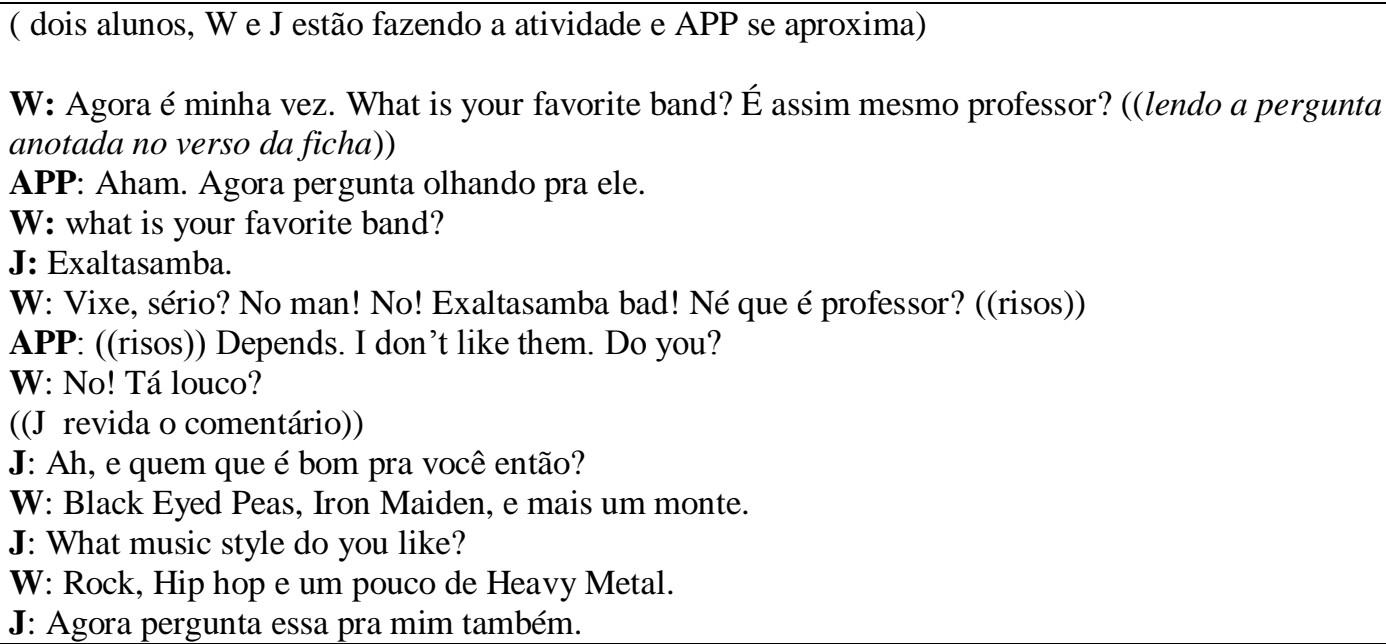

Este exemplo é um dos poucos momentos em que os colegas $\mathrm{E}$ e $\mathrm{J}$ interagem com pouco auxílio do professor, que veio junto a dupla para observá-los enquanto participavam. Quanto ao papel do professor, enquanto mediador e consequentemente par mais experiente ratificado por Lantolf e Thorne (2000, p. 274) que asseveram também que "o controle e o poder residem primariamente no professor ou par mais experiente até o momento em que o aprendiz é capaz de aceitar a responsabilidade pela tarefa ou competência em mãos”. Dessa maneira, para o incentivo de atividades orais com os alunos é necessário que os professores, que mantêm o controle e poder, enfatizem o uso da língua alvo nas aulas. Dificilmente por si só os alunos estarão motivados a querer interagir na nova língua, levando em conta as limitações em relação ao conhecimento linguístico, que atua como grande desmotivador na aprendizagem, causando o sentimento de frustração quando falta determinado vocabulário ou expressão (BROWN, 2000). Além disso, outro fator comum é o desinteresse com a aprendizagem ou com a atividade, que poderá resultar em um "fazer apenas por fazer", sem se 
preocupar com a qualidade de seu desempenho (BASSO, 2008; FERREIRA, 2008, p. 19).

O excerto seguinte (Quadro 4) retoma alguns pontos discutidos anteriormente sobre variáveis que impedem a colaboração efetiva entre os pares. O trecho a seguir mostra dois alunos tentando realizar a atividade, enquanto o outro par se dispersa e conversa durante um exercício oral.

\section{Quadro 4: Excerto 4}

(grupo de 04 alunos, dois conversando em português e outros dois debruçados sobre a carteira. $\mathrm{O}$ professor fica de frente para o grupo e reinicia a atividade com o grupo)

P: Vamos ver vocês... What's your name? ((aponta para A))

A: My name is A

P: What's your name?

T: My name is T ((e se debruça novamente sobre a carteira))

P: What music do you like? ((pergunta para $A)$ )

((V e T conversam em português, $H$ presta atenção na conversa))

A: Gospel

((V e Triem $))$

T: O que que ele falou?

P: Gospel

((V e T voltam a prestar atenção na atividade $))$

P: And you? ((para $V))$

V: Gospel também.

P: Todos vocês gostam, que legal, deixa eu fazer outra pergunta, Do you like English?

V: Yes, I dooooo ((risos))

P: Yes, You do?

V: Yes, I do so so! ((risos))

P: Ah, tah ((risos))

V: Eu sei que eu sou, so, so, so, so.

Dentre as características do scaffolding já citadas (vide Tabela 1), retomamos aqui duas: o ato de recrutar os pares a participar da atividade e de manter o foco no objetivo da mesma. Neste excerto, percebemos a dificuldade em manter o foco dos pares na atividade - recrutamento - também é possível notar o desinteresse de T, que, após responder à pergunta, volta a se debruçar na carteira. As alunas V e T não demonstram participar da atividade; no entanto, ao perceberem que os outros dois colegas ( $\mathrm{H}$ e A) estão mais engajados do que elas na atividade, $\mathrm{V}$ tenta entender o que os colegas conversam com o professor. Até que, por fim, passa a responder, ainda que brevemente, as perguntas do APP também.

O recrutamento foi feito pelo professor, porque ele sabia de aulas anteriores que os alunos daquela turma tinham em comum o fato de gostarem de música gospel, e 
vendo que a tarefa oral proposta ainda não estava sendo desempenhada a contento, fez um comentário positivo para uma das equipes em relação ao gosto musical deles. Isso parece ter despertado a atenção de alguns alunos que passaram a interagir no grupo. Podemos dizer então que o recrutamento feito pelo professor foi efetivo porque conseguiu despertar a motivação de alguns alunos, representados no excerto por V. Isto fez com que ela quisesse entender o que os colegas estavam conversando com o professor, levando-a a querer interagir também, esquecendo-se de que até segundos atrás estava dizendo não saber nada de inglês, mantendo atitude de desmotivação e desinteresse. Ela passa a dominar os turnos seguintes, falando sobre suas preferências.

À questão se os alunos gostavam de LI, V responde instantaneamente com o enunciado "Yes, I do so so" que, mesmo não estando adequado à gramática tradicional, revela uma tentativa de uso da língua inglesa, lembrando que $\mathrm{V}$ havia ficado dispersa a maior parte da atividade.

Basso (2008), discutindo a problemática envolvida no falar na língua-alvo em aulas com adolescentes, traz o posicionamento de Vygotsky (1989b) sobre as origens da fala e do pensamento. Para o autor russo, a fala surge de uma explosão de emoções e de sentimentos que não foram possíveis de serem carregadas sem serem compartilhadas com o outro. Logo, para que a fala na língua-alvo aconteça nas aulas de língua estrangeira é preciso que os interactantes sejam de fato tocados pela emoção, motivação, já que seria muito mais fácil fazer isso em língua materna, comum a todos.

Isto nos leva a confirmar que o professor tem função chave nas aulas de uma nova língua com adolescentes. Ainda que eles possam se apoiar ou buscar no outro colega ajuda para as atividades, é no professor que fica sua base, sua zona de conforto.

\section{Considerações finais}

Ao longo deste trabalho, discutimos o processo de ensino de língua inglesa com adolescentes de escola pública, com foco na análise da colaboração entre pares de alunos em atividades orais. Os dados aqui discutidos confirmam alguns pontos elencados por Ferreira (2008) a respeito das limitações entre as interações dos pares, como falta de conhecimento lingüístico ou falta de comprometimento com a atividade. Percebemos, todavia, que o aluno adolescente é recrutado a participar da tarefa quando se sente motivado pela atividade, principalmente se esta estiver voltada ao seu interesse, 
conforme apresentamos nos excertos transcritos de gravações em vídeo. Dessa maneira, o incentivo e a introdução de atividades orais nas aulas de línguas na escola pública, se trabalhados em maior escala, parecem ter potencial para familiarizar o aluno com o uso da língua alvo, além de oferecer condições para se pensar a respeito de uma aprendizagem mais significativa, em que eles estejam cientes tanto de suas habilidades individuais quanto sociais. Seriam momentos ímpares para a construção social do conhecimento e também para se transformarem intrapessoalmente (VYGOTSKY, 1989a).

Estamos certos de que é preciso alcançar algum aspecto realmente importante para que o aluno-adolescente se solte na língua-alvo em interações reais e não “engessadas" no dizer de Almeida Filho (1993). É preciso que o professor tenha criatividade, capacidade para lidar com imprevistos, introduzindo novos tópicos para o alcance de seu objetivo maior.

Concluímos este estudo cientes da complexidade de que se reveste o processo de ensino-aprendizagem de língua inglesa com adolescentes, sujeitos inseridos em um contexto sociocultural, que vivem um período marcado por mudanças diversas, e que, muitas vezes, não vêem interesse em aprender inglês na escola. Por outro lado, se motivados, estes alunos podem perceber o valor de atividades que incentivem a colaboração entre pares. Essas podem ser alternativas para lidar com o desinteresse deles pelas aulas, porque ajudariam a ver um propósito para aulas com foco na oralidade, um desafio cognitivo à altura deles, e capaz de ajudá-los a ver as aulas de línguas nas escolas públicas como parte de sua realização pessoal (BANDURA, 2006).

\section{Referências}

ALMEIDA FILHO, José Carlos. P. Linguística aplicada, ensino de línguas e comunicação. Campinas, SP: Pontes, 2005.

ARNETT, Jeffrey. J. Adolescent storm and stress, reconsidered. American Psychologist, v. 54, p. 317-326, 1999.

BASSO, Edcleia. A. Eles não querem nada com nada: uma microetnografia com adolescentes aprendendo inglês. Plurais, FECILCAM, v. 2, p. 249-253, 1999. 
A Construção Social das Competências necessárias ao Professor de Língua Estrangeira: Entre o Real e o Ideal - Um Curso de Letras em Estudo. (Tese de Doutorado em Lingüística Aplicada), Unicamp: Campinas, 2001.

Adolescentes e a aprendizagem de uma língua estrangeira: características, percepções e estratégias. In: ROCHA Claudia. H.; BASSO, Edcleia. A. (Orgs.). Ensinar e aprender língua estrangeira nas diferentes idades: reflexões para professores e formadores. São Carlos, SP: Claraluz, 2008.

BASSO, Edcleia. A.; LIMA, Fernando. S. "They haven't prepared me for that": fatores subliminares interferentes na prática docente de LE. (no prelo).

BANDURA, Albert. Adolescent development from an agentic perspective. In PAJARES, Frank; URDAN, Tim (Eds.). Self-efficacy beliefs of adolescents, Greenwich, CT: Information Age Publishing, 2006. p.1-43.

BEGLEY, Sharon. Getting inside a teen brain: hormones aren't the only reason adolescents act crazy. Their gray matter differs from children's and adults'. Newsweek, February, 28th', 2000. p.58-59.

BUCHANAN. Christy. M.; ECCLES, Jacquelynne. S.; FLANAGAN, Constance.; MIDGLEY, Carol.; FELDLAUFER, Harriet.; HAROLD, Rena .D. Parents' and teachers' beliefs about adolescents: effects of sex and experience. Journal of Youth and Adolescence., v.19, n.4, p.363-394, 1990.

BROWN, H. Douglas. Principles of language learning and teaching. 4th ed. White Plains: Longman, 2000.

CHIZZOTTI, Antonio. Pesquisa em Ciências Humanas e Sociais. São Paulo: Cortez. 2003.

COLE, Michael; WERTSCH, James. V. Beyond the individual-social antimony in discussions of Piaget and Vygotsky. 2002. Disponível em: <http://www.massey.ac.nz/ alock/virtual/colevyg.htm>. Acesso em: 24 fev 2010.

DONATO, Richard. Collective scaffolding in second language learning. In: LANTOLF, James. P.; APPEL, Gabriela. Vygotskian approaches to second language research. Norwood, NJ: Ablex,1994.

ERICKSON, Frederick. What makes school ethnography ethnographic? Anthropology and Education Quarterly, v. 15, p. 51-66, 1984.

FERREIRA, Marília. M. A fala (não tão) privada em interações de alunos realizando atividades orais em LE (inglês). 2000. Dissertação (Mestrado em Linguística Aplicada) - Instituto de Estudos da Linguagem, Unicamp, Campinas, 2000.

Constraints to peer scaffolding. Trabalhos em Linguística Aplicada. Campinas, v. 47, p. 9-29, 2008.

GIL, Antonio. C. Métodos e técnicas de pesquisa social. São Paulo: Atlas, 1999. 
JOHN-STEINER, Vera.; MAHN, Holbrook. Sociocultural Approaches to Learning and Development: A Vygotskian Framework. Educational Psychologist, v. 31, p. 191-206, 1996.

LAKATOS, Eva. M. Fundamentos de metodologia cientifica. 6 ed. São Paulo: Atlas 2007.

LAMB, Martin. 'It depends on students themselves': independent language learning at an Indonesian State School. Language, culture and curriculum, v.17, n.3, p.229-245, 2005.

LANTOLF, James. P; APPEL, Gabriela. (Orgs). Vygotskian approaches to second language research. Norwood, NJ: Ablex, 1994.

LANTOLF, James. P.; THORNE, Steven. L. Sociocultural theory and the genesis of second language development. Oxford: Oxford University Press, 2000.

LIMA, Fernando. S.; BASSO, Edcleia. A. Adolescentes aprendendo inglês com música: nos embalos da zona de desenvolvimento proximal. IV EPCT - Anais do IV Encontro de Produção Científica e Tecnológica. Campo Mourão: Editora da Fecilcam, 2009, p.113.

MACOWSKI, Edcleia Aparecida. B. A construção do ensino/aprendizagem de língua estrangeira com adolescentes. 1993. Dissertação (Mestrado em Linguística Aplicada) Instituto de Estudos da Linguagem, Unicamp, Campinas, 1993.

MARCHENKOVA, Ludmila. Language, culture and self: The Bakhtin-Vygotsky encounter. In: HALL, Joan. K.; VITANOVA, Gergana; MARCHENKOVA, Ludmila. (Eds.). Dialogue with Bakhtin on second and foreign language learning: new perspectives. Mahwah, New Jersey: Lawrence Erlbaum Associates, 2005.

MINAYO, Maria Cecília. S (Org.). Pesquisa social: teoria, método e criatividade. 17 ed. Petrópolis: Vozes. 2000.

RICHARDS, Jack. C.; PENNINGTON, Martha. C. The first year of teaching. In: RICHARDS, Jack. C. (Ed.). Beyond training. Cambridge: Cambridge University Press, 1998. p.173-190.

RICHARDS, Jack. C.; SCHMIDT, Richard. Longman dictionary of language teaching and applied linguistics. 3rd ed. London: Longman, 2002.

SCHUNK, Dale. H.; MEECE, Judith. L. Self-efficacy development in adolescents. In PAJARES, Frank; URDAN. Tim. (Eds.) Self-efficacy beliefs of adolescents. Greenwich, CT: Information Age Publishing, 2006. p. 71-96.

SMAGORINSKI, Peter. Vygotsky and the social dynamics of classrooms. English Journal,v. 97, n. 2, 2007 p.61-66.

THIOLLENT, Michel. Pesquisa-ação nas organizações. São Paulo: Atlas, 1997. 
VERENIKINA, Irina. Understanding scaffolding and the ZPD in Educational Research. Conference Papers of AARE/NZARE, Auckland, December, 2003.

Scaffolding and learning: its role in nurturing new learners. 2008. Disponível em: <http://ro.uow.edu.au/edupapers/43>. Acesso em: 24 fev 2010.

VYGOTSKY, Lev. S. Pensamento e linguagem. 2. ed. São Paulo: Martins Fontes, 1989a.

A formação social da mente. 3. ed. São Paulo: Martins Fontes, 1989b.

WOOD, David.; BRUNER, Jerome.; ROSS, Gail. The role of tutoring in problem solving. Journal of Child Psychology and Psychiatry, v.17, p-89-100, 1976.

ZARRET, Nicole.; ECCLES, Jacquelynne. The passage to adulthood: challenges of late adolescence. New Directions for Youth Development, n.111, p.13-28, 2006.

ZIMMERMAN, Barry .J.; CLEARY, Timothy .J. Adolescent's development of personal agency: the role of self-efficacy beliefs and self-regulatory skills. In: PAJARES, Frank.; URDAN. Tim. (Eds.). Self-efficacy beliefs of adolescents, Greenwich, CT: Information Age Publishing, 2006, p.45-69. 